\title{
GCU
}

Glasgow Caledonian

University

University for the Common Good

\section{Beyond virtual inclusion: communications inclusion and digital divisions}

Sinclair, Stephen; Bramley, Glen

Published in:

Social Policy and Society

DOI:

10.1017/S1474746410000345

Publication date:

2011

Document Version

Author accepted manuscript

Link to publication in ResearchOnline

Citation for published version (Harvard):

Sinclair, S \& Bramley, G 2011, 'Beyond virtual inclusion: communications inclusion and digital divisions', Social Policy and Society, vol. 10, no. 1, pp. 1-11. https://doi.org/10.1017/S1474746410000345

\section{General rights}

Copyright and moral rights for the publications made accessible in the public portal are retained by the authors and/or other copyright owners and it is a condition of accessing publications that users recognise and abide by the legal requirements associated with these rights.

Take down policy

If you believe that this document breaches copyright please view our takedown policy at https://edshare.gcu.ac.uk/id/eprint/5179 for details of how to contact us. 
Beyond Virtual Inclusion - Communications Inclusion And Digital Divisions

\section{Stephen Sinclair}

Glasgow Caledonian University

\section{Glen Bramley}

Heriot-Watt University 


\section{Beyond Virtual Inclusion - Communications Inclusion And Digital Divisions}

\section{Abstract}

Access to and engagement with information and communications technologies (ICTs) are increasingly important aspects of social inclusion. This paper draws upon analyses of UK survey data and a review of research on communications and social exclusion published in the UK between 2001 - 2006 to examine the social distribution of access to and uptake of ICTs, and explore key factors restricting the digital engagement of young people from lower income households and communities. It argues that effective strategies to bridge digital divisions in the UK must pay more attention to the social rather than technological barriers which inhibit communications inclusion. 
The ability to use information and communications technologies (ICTs) effectively has been described as 'the indispensable grammar of modern life' and a 'fundamental aspect of citizenship in the information age' (Wills quoted in Selwyn, 2002: 3). The risk of widening social divisions associated with developments in ICTs has been recognised by the UK government:

Information and communication technology has become all pervasive in our working lives and increasingly in our homes as well. How we adopt and use this technology will be crucial for our future prosperity. But there is evidence of a digital divide with some groups largely excluded from benefiting from access to the internet (Department of Trade and Industry, 2005)

Initial policies to bridge this 'digital divide' in the UK focused on increasing access to ICTs, for example through providing public internet access points, such as the People's Network of internet-connected computers in public libraries (Department of Communities and Local Government, 2008a). Despite such measures, evidence persists of social divisions in ICT use and engagement in the UK. This paper uses survey data and findings from a review of research on communications and social exclusion published in the UK between 2001 - 2006 to explore variations in ICT engagement in the UK, focusing in particular on differences between young people (Sinclair et al, 2007). These sources suggest that digital inclusion will only be achieved if the social rather than technological barriers inhibiting digital engagement are addressed. The literature on social inclusion and social capital offers lessons on how communications inclusion may be enhanced 


\section{Communications Inclusion Policy And Young People}

Achieving universal access among young people to the 'new capital' of information via ICTs has been a central goal of successive UK governments. Grouped under the umbrella of the National Grid for Learning (which ended in June 2006), this aim has been underpinned by unprecedented investment in ICT hardware, software and teacher training in schools (Furlong et al, 2000). The 2005 Digital Inclusion strategy, Connecting The UK, continued to prioritise increasing access to ICT equipment among disadvantaged groups. Measures included the Computers for Pupils programme which provided internet- connected computers for 100,000 young people in deprived neighbourhoods in England (Department of Communities and Local Government, 2008a: 39). This was accompanied by the then Department for Education and Skill's ICT and e-learning strategy, Fulfilling The Potential (BECTA, 2005). The Home Access Taskforce also launched an initiative to provide funding and support to increase ICT access and use, with the aim of achieving universal home access among households with young people aged five to 18 .

Such ambitious and expensive measures to increase the availability of ICTs represent the first phase of digital inclusion policy in the UK. However, the success of this approach is at best questionable (Loader and Keeble, 2004); for example, evaluations of initiatives such as the Wired up Communities programme concluded that the principal beneficiaries were those already among the more digitally included (Citizens Online / National Centre for Social Research, 2008). It is now widely recognised that increasing access to ICT hardware does not necessarily translate into uptake nor effective use of such opportunities among more socially excluded groups and communities. Consequently, a second phase of digital inclusion policy has recently emerged, focusing more on developing the human and social capital resources 
which enable effective digital engagement. For example, the Department of Communities and Local Government's (2008b) Communities In Control White Paper proposed piloting Digital Mentors to assist deprived communities make better use of ICTs and social media to access public services. This policy turn brings the digital inclusion discourse closer to established analyses of social inclusion (Webb, 2006).

\section{Digital Access And Engagement In The UK}

Much of the UK survey data on access to or use of ICTs refers to households. However studies of older technologies, such as TV and videocassette recorders (VCRs), suggest that household access does not necessarily mean equal access for all members within households (Facer and Furlong, 2001). Bearing this qualification in mind, it is no surprise that the data demonstrates that access to new generations of ICTs has become a mass phenomenon. For example, home PCs were available to just under one fifth of households in the mid-1990s, but this had risen to over three-fifths by $2004 / 05$ and almost three quarters by 2008 (Avery et al, 2007; ONS, 2009).

Despite this general increase in ICT access, there remain a number of well document 'sociodemographic fault lines' in ICT access (Empirica, 2006: 24). Table 1 shows that $38 \%$ of households in social class C2DE do not use the internet at all, compared with $14 \%$ of classes $A B C 1$. Education appears to be a significant influence on internet use, with the proportion of adults under 70 using the internet falling from 95\% among those with degree or higher level qualifications to only $52 \%$ among those with no qualifications (ONS 2009, Table 19). Even 
modest educational qualifications, such as having GCSE grades D-G, can raise internet usage significantly (to $78 \%$ in this case). Furthermore, this aspect of digital division may be worsening: the Oxford Internet Survey showed that the internet use gap between those with 'basic education' (secondary school only) and those with higher education widened from 35 to 44\% points between 2007 and 2009, with usage among the 'basic' group falling (Dutton et al, 2009).

Insert here:Table 1: Internet Use Location by Age, and Social Class, 2009 (GB, \%)

There is also a significant socio-geographic dimension to digital divisions. Table 2 analyses Scottish Household Survey data for 2007-08 in relation to the 2006 Scottish Index of Multiple Deprivation. This shows that $47 \%$ of adults in the most deprived fifth of neighbourhoods in Scotland never used the internet, compared with $21 \%$ in the least deprived fifth of areas. There is no evidence of an additional area effect related to deprivation compounding the influence of individual household income. Table 2 suggests that an important difference between deprived and affluent areas is the ability of people to use the internet at work as well as at home or for personal use. This underlines the importance of worklessness in deprived areas for digital engagement.

Insert here: Table 2: Location of Internet Use by Area Deprivation, Scotland 2007-08 $(\%)$

Data on age profiles of internet usage suggest that younger age groups are approaching near-universal use of the internet. Nevertheless, over one million children in the UK still have no home computer nor internet access, and they are disproportionately from disadvantaged backgrounds (Department of Communities and Local Government, 2008a: 39). The 2009 Oxford Internet Survey confirms that almost $100 \%$ of students use the internet, compared with 
$86 \%$ of employed people but only $48 \%$ of those who are unemployed (Dutton et al, 2009). Table 1 shows that in the 16-24 age group 10\% still do not use the internet, while $80 \%$ use it at home, and $44 \%$ use it at work, school or college. ICT exclusion among younger people is therefore of greatest concern for those who do not progress into further study nor employment.

Regular and informal out-of-school access to ICTs are key influences on the development of computer literacy: school pupils with home computer access are more likely to obtain more than five GCSEs and gain at least one A-level, even when controlling for household wealth and income (Schmitt and Wadsworth, 2004). Young people without home ICT access are less likely to access computers at friends' houses or in other informal settings (Facer and Furlong, 2001: 458); they are also less able than young people with home ICT access to call upon help from parents with ICT skills to overcome any problems they encounter (Citizens Online / National Centre for Social Research, 2008: 33). Limited cultural and social capital resources therefore compound the digital deprivation of young people from disadvantaged communities (Facer et al, 2001: 215).

The uses to which home computer access are put are also important factors for developing ICT skills. In particular, while using a computer for educational purposes is positively linked to educational attainment, extensive use for entertainment is negatively linked with qualifications (BECTA 2009). Not only are young people from lower income backgrounds more likely than higher income households to own entertainment technologies, such as a Playstation, ownership of such technologies is inversely related to ownership of home computers. Becker (2000) also found qualitative divisions in ICT use, with children from higher income households using home PCs for a much wider range of activities than those from lower 
income families. Reflecting this, children from higher social class households were more confident in their ICT skills. Evidence from the UK Children Go Online study indicates that divisions are evident between young people from higher and lower income household, distinguishing those for whom the internet is an increasingly rich, diverse, engaging and stimulating resource of growing importance in their lives, and those for whom it remains a narrow, unengaging if occasionally useful resource of rather less significance' (Livingstone and Bober, 2004: 415). Young people from low income households are therefore generally less skilled at using ICT for educational and vocational purposes, and are losing out on the wider communicative capacities achievable through new ICTs.

Increasing the provision and general availability of ICT equipment in schools could widen rather than reduce digital divisions (Furlong et al, 2000: 108). Not only are those of greatest concern more likely to disengage from education at a young age, even when they are in school they are less likely than more digitally literate students to have effective access to the ICT facilities provided (Facer and Furlong, 2001). The significance of supportive home and community environments in reinforcing ICT engagement and skills is such that previous investment in digital access and education may have benefited better off groups most (Hudson, 2006).

\section{Communications Inclusion And Digital Divisions}

Both survey and qualitative evidence demonstrates that digital divisions in the UK involve more than access to ICT equipment. A recurring feature of the literature on communications exclusion is criticism of simplistic ideas of the 'digital divide' as an opposition between those 
who 'have' ICT access (often equated with home internet access) and those who do not (Foley, 2004). Digital divisions are multifaceted and vary by technology, social group and degree of engagement. Selwyn (2004: 346) poses four questions which challenge simplistic ideas of the digital divide:

i. What is meant by 'ICT' - which technologies are considered?

ii. What is meant by 'access' - how does the availability of equipment vary in terms of quality of access, conditions of use and the nature of the user's experience?

iii. What is the relationship between access and use of ICTs - how are differences in the degree and nature of use considered?

iv. How are the consequences of ICT engagement considered, e.g. variations in use and communicative outputs?

As Selwyn (2004: 357) observes, 'the political and rhetorical appeal of the simplistic "digital divide" lies in its neat packaging of complex social issues in a form of social exclusion that governments can be seen to do something about' through improving ostensible ICT access. This reiterates Townsend's (1976) observation that social policy makers are inclined to convert complex multi-dimensional issues into discrete, technical and apolitical responses, as this makes them more manageable and corresponds with how organisations allocate their responsibilities. The notion of a binary division in relation to ICT encourages a narrow preoccupation with access to hardware at the expense of 'the human and social systems that must also change for technology to make a difference' (Warschauer, 2004: 6).

Consequently, there is no single digital divide, but different levels of relative ICT engagement and exclusion. Such multi-dimensionality is a feature which the concept shares with that of social inclusion. Some definitions of social inclusion have been criticised as negative or narrow; i.e. as the absence of exclusion (Cameron, 2005) or equated with labour market 
participation (Levitas, 1996). However social inclusion entails participation in society beyond mere material deprivation, and the opportunities for enhanced interaction and social participation which ICTs offer raise the possibility of a more positive and enabling conception of communications inclusion.

Communities are defined by their social relationships and interactions, and ICTs provide a mechanism for dispersed individuals to interact as a 'distributed community' (Gochenour, 2006). For example, mobile ICTs enable networked social interaction and 'gossip at-adistance [which] help people to come to terms with living in fast-paced and fragmented worlds where people less often physically bump into each other' (Fox, 2001: 11). Similarly, e-mail and social networking have become increasingly important means for elderly and disabled people to participate in social life and overcome potential isolation; as one such user explained: 'You get brain dead at home with your own company, you feel isolated, you forget how to converse, the internet can give you freedom' (Thompson and Crush, 2005: 13). ICTs are also important for minority ethnic communities maintaining communication with family and networks overseas (Foley, 2004).

Such virtual interactions have real world consequences: the UK Digital Inclusion Panel (2004: 22) concluded that 'It is now clear that the internet can be a powerful catalyst to encourage people who live in the same local community to meet and begin communicating offline in their local community'. International evidence suggests that interaction through ICTs can reduce the risk of individualisation in urban areas and enhance community cohesion (Van Winden, 2001). The opposite of such communicative capacity and networking through ICT is social isolation, or 'non-participation... in a society's mainstream institutions' (Barry, 1998: iv). 
Therefore inability use ICTs effectively risks being cut off from social relations and resources with potentially far-reaching consequences:

Being forcibly prevented from participating in a community through, for example, having one's access to the internet denied, amounts to having an aspect of one's development as a subject denied .... if economic, social, or political forces deny me my participation in a community, then they also deny me the development of an aspect of myself (Gochenour, 2006: 47)

However, policies promoting digital inclusion must recognise that communication and social inclusion is a two-way process: ICTs enable interaction and community development, but social support networks are also required to assist potential users become digitally engaged. The first phase of UK digital inclusion policy focused on addressing the material dimension of exclusion by tackling economic barriers and increasing access to ICTs. Phase two requires investing in the skills and personal competencies (cultural capital) required to enable effective use of ICT facilities, and the social support networks which make acquiring such skills worthwhile (social capital).

Computers and other ICTs enter into 'an already constituted social environment' and the responses of individuals to them are shaped by this context (Facer et al, 2001: 208). As technology is socially embedded, it is necessary to understand how far different social environments encourage and facilitate uptake and engagement with them. For example, qualitative studies demonstrate that the motivation and enthusiasm to acquire ICT skills among target groups are two important factors influencing the success of digital inclusion initiatives (BECTA, 2005). It could be argued that one potential obstacle to the successful diffusion of ICTs may be a lack of effective demand among currently excluded groups rather than any deficiency in supply. The authors of the Oxford Internet Survey distinguish between 
'digital exclusion', referring to obstacles imposed by 'the social, economic, geographical or physical situation of individuals, such as not being able to afford a computer', and 'digital choice', which describes the 'personal choices of individuals... shaped by an individual's cultural or social characteristics' (Dutton et al, 2009: 16). This distinction between structural and agency barriers inhibiting ICT engagement raises the question of whether digital divisions may be attributed in part to voluntary self-exclusion. This requires considering how far any 'choice' not to engage with ICTs has been genuinely informed and freely made (Barry, 1998). Arguably those who lack the confidence, skill or support required to develop an interest in ICTs have not exercised a genuine choice, as they have never had an opportunity to assess their potential value. As John Fisher of Citizens Online argues: 'I don't see it as a matter of choice, of people opting out. Yes, there will always be a rump of Luddites but for the vast majority they just haven't been given the choice' (quoted in Wakefield, 2005). It is therefore not technology itself which prevents digital engagement among some groups, but insufficient social impetus to exploit new communications opportunities. Sue Webb of Women Connect elaborates on this: it is not a digital divide, it is a social divide - I don't like the term digital divide because the technology doesn't divide us, it's the access, and disadvantaged groups may not have the money or the resources or the skills or the time. It's not the equipment' (quoted in Future Foundation, 2004: 13).

The implication of this view is that digital inclusion policies must consider how social frameworks of family and community might contribute to or impede young people's engagement with ICTs. Young people's enthusiasm for acquiring ICT skills and using technologies is not an entirely individual quality, but reflects their family environment, peer relationships and 'techno-popular culture' (Facer et al, 2001: 205). Neither public access nor training in schools will themselves be sufficient for ICTs to become embedded in everyday 
social practices, if community and home life do not reinforce their relevance. Digital inclusion policies based on the assumption of enthusiastic interest in digital technologies among currently unengaged groups are therefore unlikely to be successful; a prior condition is a receptive audience and social context. Recent UK government statements indicate that they recognise the importance of cultural and social capital to challenging continuing digital divisions (Department of Communities and Local Government, 2008a). This is reinforced by some hard-won lessons from other areas of social inclusion policy.

\section{Beyond Virtual Inclusion: Lessons From Social Inclusion Research}

The limited impact of technologically-driven responses to digital divisions indicates that a first step in framing a more effective digital inclusion policy must be to understand the complex social barriers inhibiting ICT engagement. A relevant lesson from other areas of social inclusion policy is that a 'bottom-up' approach to designing and delivering policy is most effective. For example, many regeneration initiatives have failed to engage with residents, and consequently did not address their principal concerns (Page, 2006). The most successful such initiatives have reflected residents' interests and been informed by active community engagement (Griggs et al, 2008). With appropriate support, those who are best placed to identify what prevents uptake of a service or to assess its quality are its intended recipients rather than those providing it (Calvert, 2007). If the perceptions and interests of excluded groups themselves are known, they can be addressed in a more sensitive way, taking account of particular circumstances and needs. This has not always been the case in social inclusion policy: 'too often the way the services are provided is patronising and disrespectful of people's lives and experiences. This is most often felt as "not being listened to" and being on 
the receiving end of highly prejudicial judgements' (Bartley, 2006: 22). This mistake has been repeated in some recent digital inclusion policies:

many projects are technologically led and flounder because of a mismatch between the communication needs and social structures of community networks and the presumed perspective of the techno enthusiasts. In many instances these groups simply don't even speak the same language let alone share a common vision (Loader and Keeble, 2004: 39)

Therefore, increasing the number or proximity of public internet access points is at best only a first step in addressing digital exclusion (Hall Aitken, 2003). To increase actual uptake, such access must be combined with appropriate community informatics strategies; i.e. actively engaging communities in using ICTs for social, community and other purposes which they value (Webb, 2006). Digital inclusion research has shown that to increase uptake and use of ICTs it is first of all necessary to stimulate the enthusiasm of those currently not engaged. Inspiring such enthusiasm among those currently indifferent to or apprehensive about ICTs requires what the Digital Inclusion Panel described as a 'compelling proposition'; i.e. the kind of 'killer application' which led to the initial mass diffusion of ICTs in the 1980s - functions which are so beneficial that people will make the effort to learn how to use ICT (Digital Inclusion Panel, 2004: 39; Cringely, 1996). For example, research on financial inclusion has found that one of the strongest motivations among those previously unbanked to open a bank account was that this is required for some satellite TV subscriptions (Financial Inclusion Taskforce, 2010). Some ICTs are already integrated into the everyday lives of young people, including those from more deprived households, through their enthusiasm for computer games and the appeal of peer communication and maintaining social contacts (Condie and Munro, 2007). These applications could form a basis from which to develop further ICT 
engagement (Livingstone and Bober, 2004), but currently such uses neither extend the broader ICT education nor range of social networks and contacts of more deprived young people. There is in fact the danger that playing games and communicating with friends locally may restrict the ICT skills and social contacts of young people from deprived communities, so that they do not acquire the cultural and bridging social capital necessary for digital inclusion is to contribute to social inclusion.

Reducing this risk requires stimulating digital engagement not only among young people themselves but among their parents, carers, and community generally. Currently the gap between relatively more ICT literature younger people and less expert older people limits the extent to which parents may encourage, assist and guide the digital engagement of younger people in lower income households and communities (Livingstone and Bober, 2004). Providing support and basic ICT skills training to parents is one way in which home life can reinforce ICT education in schools so that investment in human capital is reinforced by the development of cultural and social capital assets. Young people themselves are known to have little interest in the learning ICT skills for some future benefits (Facer et al, 2001), but adults are generally better able to appreciate the value of supporting their children's learning, if they can be engaged to do so through accessible, sensitive and responsive community-based engagement initiatives.

\section{Conclusion}

Any communications technology has both an inclusive and exclusionary potential; this is not inherent in the nature of the technology itself, but the social distributions of opportunities for access and use. While ICTs enable some people to engage in new forms of social interaction, 
they may isolate and exclude others. Debates about the future scale and nature of digital divisions in the UK are characterised by a contrast between 'cyberbole' or digital optimists on the one hand, and 'hyper-pessimism' on the other (Vaitilingam and Woolgar, 2000). Given the limitations of many definitions and measures of digital divisions, it is difficult to say with any certainty which scenario is most plausible. However, the existing research confirms Golding's (2005: 1) conclusion that, 'The "digital divide", though becoming a cliché, nonetheless describes a real schism in the experience and opportunities facing different groups in the population'. Divisions in ICT engagement reflect existing socio-economic inequalities rather than new forms of stratification, but it is evident that exclusion in the virtual world of digital communications has impact in the real world. If appropriate efforts are not made to bridge these digital divisions, socially excluded groups will suffer further marginalisation. This requires applying lessons from social policy to address divisions which are only indirectly technological. 


\section{References}

Avery, V, E. Chamberlain, Summerfield, C. and Zealey, L. (eds). (2007), Focus on the digital age, Houndmills: Palgrave Macmillan / Office of Public Sector Information.

Barry, B. (1998), Social exclusion, social isolation and the distribution of income, London: LSE, CASEpaper 12.

Bartley, M. (2006), Capability and resilience: beating the odds, London: UCL Dept of Epidemiology and Public Health / ESRC.

Becker, H. (2000), 'Who's wired and who's not: children's use of computer technology. the future of children', Children and Technology, 10, 2, 44-75.

BECTA. (2005), A good start: using ICT to enable social inclusion in primary schools, Coventry: British Educational Communications and Technology Agency.

BECTA (2009), The impact of digital technology a review of the evidence of the impact of digital technologies on formal education, Coventry: British Educational Communications and Technology Agency.

Calvert, K. (2007), 'Community planning: double vision', New Start, $13^{\text {th }}$ April, 16.

Cameron, A. (2005), 'Geographies of welfare and exclusion: initial report', Progress in Human Geography, 29, 2, 194-203

Citizens Online / National Centre for Social Research (2008), Digital exclusion profiling of vulnerable groups: young people not in education, employment or training - a profile. London: Department for Communities and Local Government.

Condie, R. and Munro, B. (2007), The impact of ICT in schools - a landscape review. Coventry: BECTA.

Cringely, R.X. (1996), Accidental empires: how the boys of silicon valley make their millions, battle foreign competition, and still can't get a date, London: Penguin

Department for Education and Skills (2003), The use of and attitudes towards ICT by people from BME groups in living deprived areas, London: Department for Education and Skills, Research Report 450.

Department of Communities and Local Government (2008a), Delivering digital inclusion: an action plan for consultation, London: Department of Communities and Local Government.

Department of Communities and Local Government (2008b), Communities in control: real people, real power, London: Department of Communities and Local Government. 
Digital Inclusion Champions (2004), Digital inclusion audit 2004: public internet access in Social Inclusion Partnership Areas, Glasgow: Scottish Enterprise.

Digital Inclusion Panel (2004), Enabling a digitally United Kingdom: a framework for action, London: Cabinet Office.

Department of Trade and Industry (2005) Connecting the UK: the digital strategy, London: Department of Trade and Industry / Cabinet Office.

Dutton, W., Helsper, E, \& Gerber, M. (2009), The Internet in Britain in 2009, Oxford: Oxford Internet Institute.

Empirica \& Work Research Centre (2006), Thematic study to analyse policy measures to promote access to information technologies as a means of combating social exclusion, Brussels: European Commission, Directorate-General for Employment, Social Affairs and Equal Opportunities.

Facer, K. and Furlong, R. (2001), 'Beyond the myth of the 'cyberkid': young people at the margins of the information revolution', Journal of Youth Studies, 4 , 4, 451-469.

Facer, K, Sutherland, R. Furlong R. and Furlong, J. (2001), 'What's the point of using computers?: the development of young people's computer expertise in the home,' New Media Society, 3, 2, 199-219.

Financial Inclusion Taskforce (2010), Mainstreaming financial inclusion: managing money and access to banking, London: HM Treasury.

Foley, P. (2004), 'Does the internet help to overcome social exclusion?' Electronic Journal of e-Government, 2, 2, 139-145.

Fox, K. (2001), Evolution, alienation and gossip: the role of mobile telecommunications in the 21st century, Oxford: Social Issues Research Centre.

Furlong, J., Furlong, R, Facer, K. and Sutherland, R. (2000), 'The national grid for learning: a curriculum without walls?', Cambridge Journal Of Education, 30, 1, 91-111.

Future Foundation (2004), The digital divide in 2025, London: British Telecom.

Gochenour. P. H. (2006), 'Distributed communities and nodal subjects', New Media \& Society, 8, 1, 33-51.

Golding, P. (2005), Communications policy and low income consumers - reflections on Ofcom consumer panel seminar, London: Ofcom. http://www.communicationsconsumerpanel.org.uk/downloads/Policy/Digital\%20Inclusio n/Low\%20Income\%20Consumers/Left\%20hand\%20navigation\%20bar/Communication s\%20Regulation\%20and\%20low\%20Income\%20Consumers/Seminar\%201\%20Reflec tions_by_Peter_Golding.pdf (accessed 19 April 2010). 
Griggs, J, Whitworth, A, Walker, R, McLennan, D. and Noble, M. (2008), Person or placebased policies to tackle disadvantage? Not knowing what works, York: Joseph Rowntree Foundation.

Hall Aitken (2003) Evaluation of CMF funded UK online centres, final report, Glasgow, Hall Aitken.

Hudson, J. (2006), Inequality and the knowledge economy: running to stand still?'. Social Policy and Society, 5, 2, 207-222.

Levitas, R. (1996). 'The concept of social exclusion and the new Durkheimian hegemony', Critical Social Policy,16, 46, 5-20.

Livingstone, S. and Bober, M. (2004), 'Taking up online opportunities? children's uses of the internet for education, communication and participation,' E-Learning And Digital Media,1, 3, 395-419

Loader, B.D. and Keeble, L. (2004). Challenging the digital divide? a literature review of community informatics initiatives, York: Joseph Rowntree Foundation.

Ofcom (2009a). Media Literacy Tracker 2009 Wave 1 tables - Children and Parents http://ww2.elitetele.com/p/ofcom-office-official-statistics/7395 (accessed 19 April 2010).

Ofcom (2009b) Ofcom Technology Tracker Q1, 2009 http://www.ofcom.org.uk/research/stats/Q1_Tech_Tracker_2009.pdf (accessed 19 April 2010)

ONS (Office for National Statistics) (2009), 'Internet Access Households and Individuals 2009', Statistical Bulletin, http://www.statistics.gov.uk/pdfdir/iahi0809.pdf (accessed 19 April 2010).

Page, R. (2006), Respect and renewal: a study of neighbourhood social regeneration, York: Joseph Rowntree Foundation.

Schmitt J and Wadsworth J (2004), Is there an impact of household computer ownership on children's educational attainment in Britain? London: Centre for Economic Performance, Discussion Paper No. 625.

Scottish Government (2009), Scottish Household Survey: Annual Report 2007-08 - Web Tables. http://www.scotland.gov.uk/Topics/Statistics/16002NebTablesAnnual2008 (accessed 19 April 2010).

Selwyn, N. (2002), "E-stablishing" an inclusive society? technology, social exclusion and UK government policy making', Journal Of Social Policy, 31, 1, 1-20.

Selwyn, N. (2004), 'Reconsidering political and popular understandings of the digital divide', New Media \& Society, 6, 3, 341-362. 
Sinclair, S, Bramley, G, Dobbie, L. and Gillespie, M. (2007), Social inclusion and communications: a review of the literature, London: Ofcom Consumer Panel.

Thompson, M. and Crush, D. (2005), Inclusion through innovation: tackling social exclusion through new technologies - qualitative research report, London: Social Exclusion Unit, Office of the Deputy Prime Minister.

Townsend, P. (1976), Sociology and social policy, Harmondsworth: Penguin.

Vaitilingam, R. and Woolgar, S. (2000), '@Ccess for all won't close the digital divide', The Edge, 3, 12-13.

Van Winden, W. (2001), 'The end of social exclusion? on information technology policy as a key to social inclusion in large European cities,' Regional Studies, 35, 9, 861-877.

Wakefield, J. (2005), Reaching out to digital refuseniks. BBC News Online, $19^{\text {th }}$ June. http://news.bbc.co.uk/1/hi/technology/4092750.stm (accessed 19 September 2008).

Warschauer, M. (2004), Technology and social inclusion: rethinking the digital divide, Cambridge, Mass: MIT Press.

Webb, S. (2006), 'Can ICT reduce social exclusion? the case of an adults' English language learning programme.' British Educational Research Journal, 32, 3, 481-507. 


\section{Tables}

Table 1: Internet Use Location by Age, and Social Class, 2009 (GB, \%)

\begin{tabular}{|l|cccccl|}
\hline Internet Use Location & $16-24$ & $25-34$ & $35-44$ & $45-54$ & $55-64$ & 65 over \\
\hline PC/Laptop at home & 80 & 79 & 86 & 74 & 59 & 36 \\
At Work/School/College & 44 & 41 & 42 & 42 & 12 & 6 \\
Other Location & 35 & 27 & 13 & 10 & 11 & 10 \\
Portable Device & 58 & 38 & 38 & 31 & 16 & 6 \\
Do Not Use & 10 & 11 & 10 & 17 & 39 & 61 \\
\hline Internet Use Location & $\mathrm{ABC} 1$ & $\mathrm{C} 2 \mathrm{DE}$ & $\mathrm{All}$ & & & \\
PC/Laptop at home & 82 & 52 & 69 & & & \\
At Work/School/College & 46 & 13 & 31 & & & \\
Other Location & 17 & 18 & 17 & & & \\
Portable Device & 32 & 29 & 31 & & & \\
Do Not Use & 14 & 38 & 25 & & & \\
\cline { 1 - 4 } & & & & &
\end{tabular}

Source: Ofcom Media Literacy Tracker 2009, Table 87

Table 2: Location of Internet Use by Area Deprivation, Scotland 2007-08 (\%)

\begin{tabular}{lcccccc}
\hline Area Deprivation & $\begin{array}{c}\text { Most } \\
\text { deprived }\end{array}$ & & \multicolumn{4}{c}{$\begin{array}{c}\text { Least } \\
\text { deprived }\end{array}$} \\
SIMD Quintile & 1 & 2 & 3 & 4 & 5 & Scotland \\
\hline Never use the internet & 47 & 41 & 33 & 26 & 21 & 33 \\
Work use only & 2 & 2 & 2 & 2 & 2 & 2 \\
Personal use only & 33 & 34 & 33 & 34 & 31 & 33 \\
Both work and personal use & 18 & 23 & 32 & 38 & 46 & 31 \\
All & 100 & 100 & 100 & 100 & 100 & 100 \\
Base & 4,733 & 5,046 & 5,421 & 5,085 & 4,325 & 24,610 \\
\hline
\end{tabular}

Source: Scottish Government (2009) Scottish Household Survey 2007-08, Table, 9.1.9 